\title{
EFFECT OF FEEDING DIFFERENT OILS ON PLASMA CORTICOSTERONE IN BROILER CHICKENS
}

\author{
László PÁL ${ }^{1 *}$, Margit KULCSÁR ${ }^{2}$, Judit PoóR ${ }^{3}$, László WÁGNER ${ }^{1}$, Szabolcs NAGY ${ }^{1}$, \\ Károly DUBLECZ ${ }^{1}$ and Ferenc HusvéTH ${ }^{1}$ \\ ${ }^{1}$ Department of Animal Science and ${ }^{3}$ Department of Economic Methodology, \\ Georgikon Faculty, University of Pannonia, Deák F. u. 16, H-8361 Keszthely, Hungary; \\ ${ }^{2}$ Department and Clinic of Obstetrics and Reproduction, Faculty of Veterinary Science, \\ Szent István University, Budapest, Hungary
}

(Received 27 August 2014; accepted 17 February 2015)

\begin{abstract}
A study was conducted to examine the effects of different oils on the plasma corticosterone concentrations of broiler chickens fed ad libitum or deprived of feed for 24 hours. A total of 36 Ross broilers were randomly assigned to one of three dietary treatments at 10 days of age and fed a grower diet supplemented with $60 \mathrm{~g} / \mathrm{kg}$ soybean oil (rich in linoleic acid, C18:2n-6), linseed oil (rich in $\alpha$-linolenic acid, C18:3n-3) or fish oil (rich in C14:0, C16:0, C16:1n-7, C20:1n-9; eicosapentaenoic acid and docosahexaenoic acid, EPA, C20:5n-3 and DHA, C22:6n-3), respectively, for 18 days. Dietary supplementation of fish oil resulted in lower $(\mathrm{P}<0.05)$ baseline plasma corticosterone levels of chickens fed ad libitum for 18 days compared to soybean and linseed oil supplementations. Feed deprivation for $24 \mathrm{~h}$ induced a significant $(\mathrm{P}<0.05)$ increase in corticosterone concentration in every treatment group compared to the ad libitum-fed birds. The hormone levels of feed-deprived birds did not differ significantly among groups fed diets supplemented with different oils.
\end{abstract}

Key words: Polyunsaturated fatty acids, fish oil, plasma corticosterone, broiler chickens

Polyunsaturated fatty acids (PUFA) influence normal growth and development, gene expression, metabolic pathways, as well as central nervous, endocrine and immune functions (Simopoulos, 2003). Dietary n-3 and n-6 subtypes of PUFA have been shown to fulfil different physiological roles in metabolism and hormonal regulation. In mammals, diets containing high levels of n-6 PUFA may lead to insulin resistance while the incorporation of long-chain n-3 PUFA in phospholipids of skeletal muscle cells improves glucose uptake and insulin action (Storlien et al., 1991). The n-6 fatty acid arachidonic acid (AA; C20:4n-6) can be converted to eicosanoids of high pro-inflammatory potential (Lewis et al., 1990). By contrast, the n-3 fatty acids eicosapentaenoic acid (EPA; C20:5n-3)

*Corresponding author; E-mail: pal-1@georgikon.hu; Phone: 0036 (83) 545-376; Fax: 0036 (83) 545-143 
and docosahexaenoic acid (DHA; C22:6n-3) give rise to mediators that have been demonstrated to be anti-inflammatory and inflammation-resolving (Serhan et al., 2000). The metabolic effects of dietary PUFA have also been investigated in broiler chickens. In the fasted state, broilers fed diets enriched with n- 6 or n-3 fatty acids (sunflower or linseed oil, respectively) developed lower plasma levels of insulin and cholesterol compared to those fed diets rich in saturated fatty acids (tallow) or monounsaturated fatty acids (different kinds of olive oils; Crespo and Esteve-Garcia, 2003). The protective effects of EPA and DHA from marine sources are well documented in chronic human and animal diseases including cancer, insulin resistance and cardiovascular disease (Calder, 2012). However, the specific biological effects of plant-derived $\alpha$-linolenic acid (ALA; C18:3n-3) are largely unknown or conflicting (Anderson and Ma, 2009).

Recent studies in mammals have demonstrated that EPA and DHA may affect the function of the hypothalamic-pituitary-adrenal (HPA) axis and inhibit corticosterone secretion (Carsia et al., 2008; Liu et al., 2013). However, little information is available in birds whether ALA and its longer chain metabolites, EPA and DHA show similar or different metabolic effects on the adrenocortical function to those found in mammalian species. Thus, the aim of the present study was to examine the effects of different dietary sources of PUFA - soybean oil (rich in LA), linseed oil (rich in ALA) and fish oil (rich in EPA + DHA) - on plasma corticosterone concentrations.

\section{Materials and methods}

\section{Animals, diets and experimental design}

The experimental procedures, animal facilities and sample collection methods were approved by the National Ethics Committee for Animal Experiments of the Advisory Council on Animal Experiments (permit number: GK-2676/2012). One-day-old male broiler chickens of the Ross 308 strain were obtained from a commercial hatchery and assigned randomly to three floor pens, with 12 chickens per pen in an environmentally controlled room under standard conditions of temperature, humidity and ventilation (Aviagen Broiler Breeders, 2009).

Broilers were fed a commercial broiler starter diet until 10 days of age. At 10 days of age, the chickens were randomly assigned to one of three dietary treatments ( $\mathrm{n}=12$ per treatment) and fed the experimental grower diets for 18 days on an ad libitum basis. Individual body weights and feed intake per group were measured at 10 and 28 days of age, and body weight gain and feed conversion ratio was calculated. The experimental diets were isonitrogenous and isoenergetic, and differed only in fatty acid composition. The diets were prepared weekly and stored below $20^{\circ} \mathrm{C}$. The composition and nutrient content of the experimental diets are presented in Table 1 . The experimental diets were supple- 
mented with $60 \mathrm{~g} / \mathrm{kg}$ edible-grade soybean, linseed or fish oil, respectively. The fatty acid composition of the diets is shown in Table 2.

\section{Table 1}

Composition and nutrient content of the experimental diets

\begin{tabular}{lc}
\hline Ingredient & $\mathrm{g} / \mathrm{kg}$ \\
\hline Maize & 422 \\
Wheat & 150 \\
Extracted soybean meal & 275 \\
Maize gluten meal & 50 \\
Oil & 60 \\
L-Lysine & 3 \\
DL-Methionine & 1 \\
Monocalcium phosphate & 15 \\
Limestone & 16 \\
Salt & 3 \\
Vitamin-trace mineral premix $\dagger$ & 5
\end{tabular}

Calculated nutrient content:

\begin{tabular}{lr}
\hline Metabolisable energy (AMEn, MJ/kg) & 13.2 \\
Crude protein & 210.0 \\
Ether extract & 82.8 \\
Crude fibre & 35.0 \\
Calcium & 9.0 \\
Phosphorus (available) & 4.5 \\
Lysine & 12.5 \\
Methionine & 4.6 \\
Methionine + cystine & 8.8
\end{tabular}

*Soybean, linseed or fish oil, respectively. The oils contained $1 \mathrm{mg} / \mathrm{g}$ added antioxidant (butylated hydroxytoluene); $†$ Supplied the following per $\mathrm{kg}$ of diet: trans-retinol $3.3 \mathrm{mg}$, cholecalciferol $125 \mu \mathrm{g}$, DL- $\alpha$-tocopheryl acetate $50 \mathrm{mg}$, menadione $3 \mathrm{mg}$, thiamine $2 \mathrm{mg}$, riboflavin $6 \mathrm{mg}$, pyridoxine $3 \mathrm{mg}$, cyanocobalamin $16 \mu \mathrm{g}$, D-calcium panthotenate $20 \mathrm{mg}$, niacin $20 \mathrm{mg}$, folic acid $1.75 \mathrm{mg}$, choline chloride $600 \mathrm{mg}$, butylated hydroxytoluene $80 \mathrm{mg}, \mathrm{Zn}$ $80 \mathrm{mg}$, Fe $80 \mathrm{mg}$, Mn $100 \mathrm{mg}$, Cu $8 \mathrm{mg}$, I $1 \mathrm{mg}$, Se $150 \mu \mathrm{g} ; \ddagger$ Based on analyses of ingredients

\section{Sample collection and chemical analyses}

Blood samples were collected from the wing vein of ad libitum-fed birds in heparinised tubes containing sodium fluoride at day 28 between 08:00 and 09:00 a.m. After blood sampling, chickens in each group were deprived of feed for $24 \mathrm{~h}$. Blood sampling was repeated the next day between 08:00 and 09:00 a.m. Care was taken to ensure that the time that elapsed between catching a bird 
and collecting the blood sample did not exceed $45 \mathrm{sec}$ to minimise the effects of sampling on hormone and metabolite values. Plasma was obtained after centrifugation at $4,000 \mathrm{rpm}$ for 20 min within $1 \mathrm{~h}$ of collection and stored at $-20^{\circ} \mathrm{C}$.

Table 2

Fatty acid composition of the experimental diets ( $\mathrm{g} / 100 \mathrm{~g}$ total fatty acids extracted)

\begin{tabular}{lccr}
\hline & \multicolumn{3}{c}{ Dietary treatments $^{*}$} \\
\cline { 2 - 4 } Fatty acids & Soybean oil & Linseed oil & Fish oil \\
\hline $14: 0$ & 0.32 & 0.11 & 6.48 \\
$16: 0$ & 10.04 & 7.95 & 17.28 \\
$18: 0$ & 3.24 & 3.92 & 2.28 \\
$16: 1 \mathrm{n}-7$ & 0.11 & 0.11 & 4.68 \\
$18: 1 \mathrm{n}-9$ & 24.62 & 22.05 & 18.72 \\
$18: 1 \mathrm{n}-7$ & 0.76 & 0.42 & 1.32 \\
$20: 1 \mathrm{n}-9$ & 0.22 & 0.21 & 7.32 \\
$18: 2 \mathrm{n}-6$ & 54.00 & 25.55 & 20.28 \\
$18: 3 \mathrm{n}-3$ & 5.51 & 38.90 & 2.64 \\
$20: 5 \mathrm{n}-3$ & 0.32 & 0.21 & 8.40 \\
$22: 5 \mathrm{n}-3$ & $\mathrm{ND}$ & 0.21 & 0.84 \\
$22: 6 \mathrm{n}-3$ & $\mathrm{ND}$ & $\mathrm{ND}$ & 9.72 \\
Total saturated & 13.61 & 11.98 & 26.04 \\
Total monounsaturated & 25.70 & 22.79 & 32.04 \\
Total polyunsaturated & 59.83 & 64.87 & 41.88 \\
n-6 & 54.00 & 25.55 & 20.28 \\
n-3 & 5.83 & 39.32 & 21.60 \\
n-6: n-3 & 9.26 & 0.65 & 0.94 \\
\hline
\end{tabular}

$\mathrm{ND}=$ not detected; ${ }^{*}$ Diets supplemented with $60 \mathrm{~g} / \mathrm{kg}$ soybean oil, linseed oil or fish oil, respectively

Plasma corticosterone levels were measured by a high-sensitivity competitive enzyme-linked immunoassay method (Code AC-15F1, IDS Ltd, UK) using an Anthos Zenyth 3100 microplate reader (Biochrom Co., UK). In this analysis the intra-assay coefficient of variation (CV) was $<10 \%$.

The total fat content of the diets was extracted and lipid extracts were converted to fatty acid methyl esters by using $\mathrm{BF}_{3}$-methanol (Association of Official Analytical Chemists, $1990 a, 1990 b$ ). The fatty acid methyl esters were separated and analysed by gas chromatography in a TRACE 2000 chromatograph (Thermo Finnigan Italia, S.p.A., Rodano, Milan, Italy) equipped with an Omegavax 320 capillary column $(30 \mathrm{~m}$ length $\times 0.32 \mathrm{~mm}$ I.D., $0.25 \mu \mathrm{m}$ film; Supelco, Bellefonte, USA). The temperature of oven and flame ionisation detector were set at 200 and $260{ }^{\circ} \mathrm{C}$, respectively. Helium was used as a carrier gas $(25 \mathrm{~cm} / \mathrm{sec}$, set at $200{ }^{\circ} \mathrm{C}$ ) and the split ratio was $100: 1$. Individual fatty acids were identified by comparison to a known standard mixture of fatty acid methyl esters (PUFA-2, Supelco catalogue number 4-7015-U; Supelco, Bellefonte, PA, USA). 


\section{Statistical analysis}

Statistical analysis of plasma corticosterone concentrations was carried out by two-way analysis of variance (ANOVA) using dietary fatty acid profile and feeding regimen (ad libitum feeding vs. feed deprivation) as main effects. Differences between means were determined by the Duncan multiple range test and considered significant when $\mathrm{P}<0.05$. Data for corticosterone concentrations were transformed logarithmically before ANOVA to achieve homogeneity of variances. The significance level of correlation coefficients between dietary fatty acids and baseline corticosterone levels was evaluated by $t$-test. All statistical analyses were conducted using the Statistica 5.0 statistical software (StatSoft, Tulsa, OK, USA). The results are presented as mean values with their standard errors.

\section{Results}

The body weight of birds fed different diets did not differ $(\mathrm{P}>0.05)$ at 28 days of age (Table 3 ). The body weight gain and feed conversion ratio of chickens during the experimental period (from day 10 to day 28) were not affected by dietary treatments $(\mathrm{P}>0.05$; Table 3$)$.

Table 3

Body weight (g), body weight gain (g/day) and feed conversion ratio $(\mathrm{kg} / \mathrm{kg})$ of birds fed diets supplemented with different oils

\begin{tabular}{lcccc}
\hline & \multicolumn{3}{c}{ Dietary treatments ${ }^{*}$} & P value \\
\cline { 2 - 4 } & Soybean oil & Linseed oil & Fish oil & \\
\hline Body weight (day 28) & $1437.4 \pm 43.9$ & $1367.6 \pm 43.3$ & $1329.4 \pm 30.8$ & NS \\
Body weight gain (days 10-28) & $51.9 \pm 2.0$ & $50.9 \pm 1.2$ & $49.8 \pm 1.3$ & NS \\
Feed conversion ratio (days 10-28) & 1.56 & 1.56 & 1.59 & - \\
\hline
\end{tabular}

Body weight and body weight gain values are means \pm SE of 12 birds. Feed conversion ratio values are means calculated from the feed intake data measured for the whole treatment groups. NS $=$ not significant, P > 0.05; ' Diets supplemented with $60 \mathrm{~g} / \mathrm{kg}$ soybean oil, linseed oil or fish oil, respectively

The plasma corticosterone results of chickens fed ad libitum and deprived of feed for $24 \mathrm{~h}$ are shown in Fig. 1. Dietary supplementation of soybean and linseed oil resulted in higher basal plasma corticosterone levels compared to fish oil supplementation $(\mathrm{P}<0.05)$. Feed deprivation for $24 \mathrm{~h}$ induced an increase $(\mathrm{P}<$ 0.05 ) in corticosterone concentration in all treatment groups compared to the baseline values of ad libitum-fed birds. The hormone levels of feed-deprived birds did not differ significantly between groups fed different diets. The correlation coefficients between the proportion of fatty acids in diets and basal plasma corticosterone levels are presented in Table 4 . The proportion of dietary fatty ac- 
ids C14:0, C16:1n-7, C20:1n-9, C20:5n-3 and total saturated fatty acids showed a negative correlation with the plasma corticosterone values observed in the three dietary treatment groups $(\mathrm{P}<0.05)$.

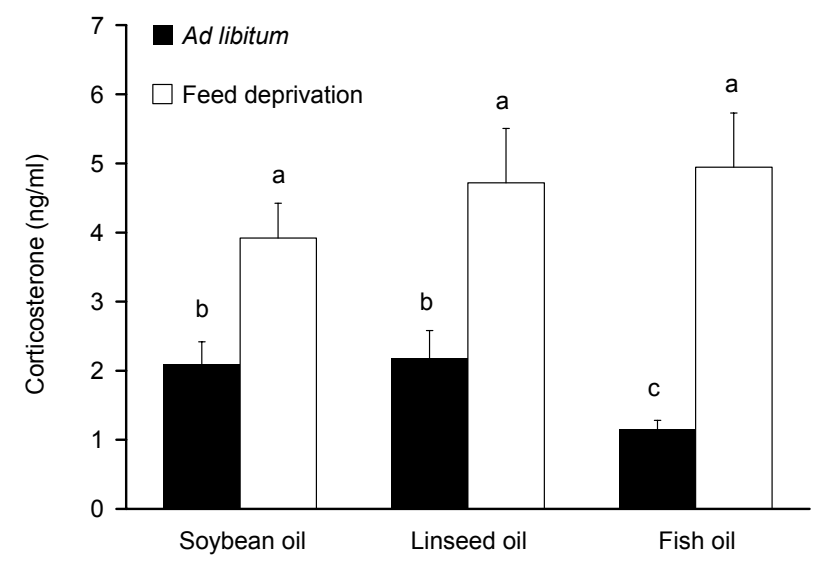

Fig. 1. Effect of dietary treatments on plasma corticosterone levels of broilers fed ad libitum or deprived of feed for $24 \mathrm{~h}$ ( $\mathrm{n}=12$ per dietary treatment group). Chickens were fed diets supplemented with $60 \mathrm{~g} / \mathrm{kg}$ soybean oil, linseed oil or fish oil, respectively. Values are means with their standard errors. Values not sharing common superscript letters are significantly different $(\mathrm{P}<0.05)$

\section{Table 4}

Correlation coefficients (r) between dietary fatty acids and baseline plasma corticosterone concentrations

\begin{tabular}{lcc}
\hline Fatty acids & $\mathrm{r}$ & $\mathrm{P}$ value \\
\hline $14: 0$ & -0.9988 & $<0.05$ \\
$16: 0$ & -0.9908 & $\mathrm{NS}$ \\
$18: 0$ & 0,9406 & $\mathrm{NS}$ \\
$16: 1 \mathrm{n}-7$ & -0.9969 & $<0.05$ \\
$18: 1 \mathrm{n}-9$ & 0.8637 & $\mathrm{NS}$ \\
$18: 1 \mathrm{n}-7$ & -0.9540 & $\mathrm{NS}$ \\
$20: 1 \mathrm{n}-9$ & -0.9970 & $<0.05$ \\
$18: 2 \mathrm{n}-6$ & 0.5567 & $\mathrm{NS}$ \\
$18: 3 \mathrm{n}-3$ & 0.6240 & $\mathrm{NS}$ \\
$20: 5 \mathrm{n}-3$ & -0.9977 & $<0.05$ \\
Total saturated & -0.9996 & $<0.05$ \\
Total monounsaturated & -0.9728 & $\mathrm{NS}$ \\
Total polyunsaturated & 0.9914 & $\mathrm{NS}$ \\
$\mathrm{n}-6$ & 0.5567 & $\mathrm{NS}$ \\
$\mathrm{n}-3$ & 0.1123 & $\mathrm{NS}$ \\
$\mathrm{n}-6: \mathrm{n}-3$ & 0.4032 & $\mathrm{NS}$ \\
\hline
\end{tabular}

$\mathrm{NS}=$ not significant, $\mathrm{P}>0.05$ 


\section{Discussion}

This experiment focused on studying the effect of dietary fatty acids on plasma corticosterone concentrations in broilers. Plasma corticosterone level has been widely used as the most reliable indicator of acute stress in chickens (Thaxton and Puvadolpirod, 2000). Considering the age of the broilers, in this study the mean basal levels of this hormone in birds fed ad libitum were in the physiological range (Gonzales et al., 2003). Peak corticosterone concentrations after acute handling stress can reach a value ranging from 4 to $16 \mathrm{ng} / \mathrm{ml}$ (Beuving and Vonder, 1978). In conformity with the results of Scott et al. (1983), our study clearly showed that a 24-h feed deprivation significantly increased plasma corticosterone concentration in broilers irrespective of dietary treatments, and such feed deprivation led to the activation of the HPA axis.

To the best of our knowledge, this paper presents the first experimental demonstration of the effects of dietary fatty acids on plasma corticosterone concentrations in poultry. The ad libitum feeding of diets containing fish oil led to significantly lower baseline plasma corticosterone concentrations than the feeding of diets supplemented with either soybean or linseed oil. In contrast, we did not find significant dietary fatty acid effects on plasma corticosterone concentrations in response to feed deprivation.

In this experiment, correlations were found between several dietary fatty acids (saturated: C14:0; monounsaturated: C16:1n-7, C20:1n-9; and polyunsaturated: EPA, respectively) and baseline plasma corticosterone levels. These findings may contribute to the significant differences observed in our study. Circulating specific free fatty acids in the plasma are involved in the regulation of HPA axis activity. A fall of plasma palmitate, but not of oleate and linoleate, level can increase plasma corticosterone in rats (Oh et al., 2014). Thus, a higher intake of dietary palmitate may decrease plasma corticosterone. In our experiment, broilers fed diets containing fish oil had a higher intake of palmitate than chickens in other groups, and thus the effect of palmitate cannot be excluded. The correlation coefficient for palmitate was quite high but not significant. Based on the literature published on this topic, the possible role of the long-chain n-3 fatty acids EPA and DHA in the inhibition of corticosterone synthesis and/or secretion in broilers fed a diet containing fish oil can be supposed. Like in our study, however, most of the experimental setups did not allow the precise investigation of the effects of individual fatty acids. According to a single study published in birds up to now, a diet containing higher amounts of n-3 type fatty acids of marine origin resulted in lower levels of plasma corticosterone. In that experiment of Kitaysky et al. (2001) with feed-restricted red-legged kittiwake chicks at $65 \%$ of the ad libitum energy intake, a high-lipid diet rich in long-chain n-3 PUFA resulted in lower baseline and acute stress-induced levels of corticosterone compared to a low-lipid diet of the same fatty acid composition. Similarly, several 
studies in mammals investigating the effects of dietary fatty acids also demonstrated the suppressive effect of long-chain n-3 fatty acids on the adrenocortical function both at adrenal and hypothalamic-pituitary level. Compared to the diet supplemented with butterfat rich in saturated fatty acids, feeding a diet supplemented with an n-3 fatty acid mixture containing EPA and DHA decreased cellular ACTH-induced corticosteroid production of rats by $67 \%$ (Carsia et al., 2008). In a recent study in piglets, a diet supplemented with fish oil resulted in the enrichment of EPA and DHA contents, respectively, in the hypothalamus and pituitary, and decreased plasma ACTH and cortisol levels (Liu et al., 2013). Mice fed diets supplemented with DHA showed significantly reduced hypothalamic corticotropin-releasing hormone $(\mathrm{CRH})$ and pituitary ACTH levels, as well as reduced plasma ACTH and corticosterone in response to physical stress (Jiang et al., 2012).

Despite the experiments demonstrating the effect of long-chain n-3 PUFA on the HPA axis, the precise mechanism of that effect is still not clear. Different modes of n-3 PUFA action were observed, including effects on plasma membrane structure in model systems (Shaikh, 2012), and as ligands for peroxisome proliferator-activated receptors of rat cardiomyocytes (Di Nunzio et al., 2009) and specific G-protein-coupled receptors of humans and mice (Oh and Olefsky, 2012). In addition, EPA and DHA may impair prostaglandin synthesis in a state of inflammation and serve as a substrate for recently discovered lipid mediators which in turn affect the HPA function of mammalian species (Peterson et al., 1998; Shewchuk, 2014). Prostaglandins can stimulate ACTH secretion, and previous in vitro studies with chicken and turkey adrenal cells showed that prostaglandins can directly increase avian adrenocortical steroidogenesis (Kocsis et al., 1999).

In our experiment feeding a fish oil diet rich in long-chain marine-type EPA plus DHA and a diet containing high amounts of ALA of linseed oil origin resulted in significantly different baseline plasma corticosterone levels of ad libitum-fed chickens. Supposing the role of EPA and DHA in the regulation of plasma baseline corticosterone, the n-3 fatty acid ALA did not seem to have similar effects. The enzymatic conversion of ALA to EPA and DHA is possible in chickens (Gregory et al., 2013), but its efficiency does not seem to be sufficient to have effects similar to those of the long-chain n-3 PUFA in fish oil diets. Furthermore, the biological role of ALA in mammalian stress response is also unknown (Anderson and Ma, 2009).

Despite the numerous examples in mammals mentioned above, dietary fatty acids did not affect the plasma corticosterone response of chickens to feed deprivation. The reason for this is not clear and could be related to differences between the mammalian species investigated and chickens. However, in another experiment conducted by us a three-day feed restriction led to a significantly lower increase of corticosterone metabolite concentration in the faeces of hens 
fed a diet containing fish oil compared to a diet supplemented with sunflower oil (unpublished results).

In conclusion, the present study indicates that feeding diets supplemented with fish oil can decrease the baseline plasma corticosterone concentration of chickens fed ad libitum compared to those receiving diets containing soybean or linseed oils, respectively. These effects observed in broilers may be related to several dietary fatty acids present in fish oil, and further studies on the effect exerted by individual fatty acids on the HPA axis and corticosterone level of birds need to be conducted.

\section{Acknowledgements}

The study presented in this paper was conducted in the framework of the project TÁMOP-4.2.2.A-11/1/KONV-2012-0064. The project is implemented with support from the European Union, with co-funding provided by the European Social Fund.

\section{References}

Anderson, B. M. and Ma, D. W. (2009): Are all n-3 polyunsaturated fatty acids created equal? Lipids in Health and Disease 8, 33.

Association of Official Analytical Chemists (1990a): Fat (crude) or ether extract in animal feed (920.39). In: Helrich, K. (ed.) Official Methods of Analysis. AOAC, Arlington, VA. p. 79.

Association of Official Analytical Chemists (1990b): Fatty acids in oils and fats. Preparation of methyl esters. Esterification in presence of sulfuric acid (965.49). In: Helrich, K. (ed.) Official Methods of Analysis. AOAC, Arlington, VA. p. 963.

Aviagen Broiler Breeders (2009): Ross Broiler Management Manual. Aviagen Group, Midlothian, Scotland. pp. 1-114.

Beuving, G. and Vonder, G. M. (1978): Effect of stressing factors on corticosterone levels in the plasma of laying hens. Gen. Comp. Endocrinol. 35, 153-159.

Calder, P. C. (2012): Mechanisms of action of (n-3) fatty acids. J. Nutr. 142, 592S-599S.

Carsia, R. V., Weber, H., Mcllroy, P. J. and Hock, C. E. (2008): Long-term dietary lipid regimen alters adrenocortical function at the cellular level. Horm. Metab. Res. 40, 848-853.

Crespo, N. and Esteve-Garcia, E. (2003): Polyunsaturated fatty acids reduce insulin and very low density lipoprotein levels in broiler chickens. Poultry Sci. 82, 1134-1139.

Di Nunzio, M., Danesi, F. and Bordoni, A. (2009): N-3 PUFA as regulators of cardiac gene transcription: a new link between PPAR activation and fatty acid composition. Lipids 44, 1073-1079.

Gonzales, E., Kondo, N., Saldanha, E. S., Loddy, M. M., Careghi, C. and Decuypere, E. (2003): Performance and physiological parameters of broiler chickens subjected to fasting on the neonatal period. Poultry Sci. 82, 1250-1256.

Gregory, M. K., Geier, M. S., Gibson, R. A. and James, M. J. (2013): Functional characterization of the chicken fatty acid elongases. J. Nutr. 143, 12-16.

Jiang, L. H., Liang, Q. Y. and Shi, Y. (2012): Pure docosahexaenoic acid can improve depression behaviour and affect HPA axis in mice. Eur. Rev. Med. Pharmacol. Sci. 16, 1765-1773.

Kitaysky, A. S., Kitaiskaia, E. V., Wingfield, J. C. and Piatt, J. F. (2001): Dietary restriction causes chronic elevation of corticosterone and enhances stress response in red-legged kittiwake chicks. J. Comp. Physiol. B 171, 701-709. 
Kocsis, J. F., Rinkardt, N. E., Satterlee, D. G., Weber, H. and Carsia, R. V. (1999): Concentrationdependent, biphasic effect of prostaglandins on avian corticosteroidogenesis in vitro. Gen. Comp. Endocrinol. 115, 132-142.

Lewis, R. A., Austen, K. F. and Soberman, R. J. (1990): Leukotrienes and other products of the 5lipoxygenase pathway. Biochemistry and relation to pathobiology in human diseases. N. Eng. J. Med. 323, 645-655.

Liu, Y., Chen, F., Li, Q., Odle, J., Lin, X., Zhu, H., Pi, D., Hou, Y., Hong, Y. and Shi, H. (2013): Fish oil alleviates activation of the hypothalamic-pituitary-adrenal axis associated with inhibition of TLR4 and NOD signaling pathways in weaned piglets after a lipopolysaccharide challenge. J. Nutr. 143, 1799-1807.

Oh, D. Y. and Olefsky, J. M. (2012): Omega 3 fatty acids and GPR120. Cell Metab. 15, 564-565.

Oh, Y. T., Kim, J., Kang, I. and Youn, J. H. (2014): Regulation of hypothalamic-pituitary-adrenal axis by circulating free fatty acids in male Wistar rats: role of individual free fatty acids. Endocrinology 155, 923-931.

Peterson, L. D., Jeffery, N. M., Thies, F., Sanderson, P., Newsholme, E. A. and Calder, P. C. (1998): Eicosapentaenoic and docosahexaenoic acids alter rat spleen leukocyte fatty acid composition and prostaglandin E2 production but have different effects on lymphocyte functions and cell-mediated immunity. Lipids 33, 171-180.

Scott, T. R., Satterlee, D. G. and Jacobs-Perry, L. A. (1983): Circulating corticosterone responses of feed and water deprived broilers and Japanese quail. Poultry Sci. 62, 290-297.

Serhan, C. N., Clish, C. B., Brannon, J., Colgan, S. P., Chiang, N. and Gronert, K. (2000): Novel functional sets of lipid-derived mediators with antiinflammatory actions generated from omega-3 fatty acids via cyclooxygenase 2-nonsteroidal antiinflammatory drugs and transcellular processing. J. Exp. Med. 192, 1197-1204.

Shaikh, S. R. (2012): Biophysical and biochemical mechanism by which dietary n-3 polyunsaturated fatty acids from fish oil disrupt membrane lipid rafts. J. Nutr. Biochem. 23, 101-105.

Shewchuk, B. M. (2014): Prostaglandins and n-3 polyunsaturated fatty acids in the regulation of the hypothalamic-pituitary axis. Prostaglandins Leukot. Essent. Fatty Acids 91, 277-287.

Simopoulos, A. P. (2003): Essential fatty acids in health and chronic diseases. Forum Nutr. 56, 67-70.

Storlien, L. H., Jenkins, A. B., Chisholm, D. J., Pascoe, W. S., Khi, S. and Kraegen, E. W. (1991): Influence of dietary fat composition on development of insulin resistance in rats. Diabetes 40, 280-289.

Thaxton, J. P. and Puvadolpirod, S. (2000): Model of physiological stress in chickens. 5. Quantitative evaluation. Poultry Sci. 79, 391-395. 